\title{
Intention to Use and Satisfaction of e-Learning for Training in the Corporate Context
}

\author{
Maxine Esterhuyse, Brenda Scholtz, and Danie Venter \\ Nelson Mandela Metropolitan University, \\ Port Elizabeth, South Africa
}

\section{Maxine.Esterhuyse@nmmu.ac.za Brenda.Scholtz@nmmu.ac.za \\ Danie.Venter@nmmu.ac.za}

\begin{abstract}
Together, the fields of education and information technology have identified the need for an online solution to training. The introduction of e-learning has optimised the learning process, allowing organisations to realise the many advantages that e-learning offers. The importance of user involvement in the success of e-learning makes it imperative that the forces driving intention to use e-learning and satisfaction thereof be determined. The purpose of this paper is to investigate the relationships between the metrics influencing intention to use and the satisfaction of using e-learning in companies.

The results of a survey distributed amongst a South African software development company's customer base revealed that the 94 respondents have positive enjoyment and self-efficacy levels, and low computer anxiety levels. Correlation analysis revealed significant relationships between enjoyment and self-efficacy and between enjoyment and satisfaction. Companies should therefore ensure that users enjoy using e-learning as it can directly influence satisfaction and self-efficacy.
\end{abstract}

Keywords: e-learning, intention, satisfaction, survey, self-efficacy, enjoyment, computer anxiety

\section{Introduction}

Corporations functioning in unstable and competitive markets have to acknowledge the importance of human capital so that employees' skill sets can be leveraged to gain competitive advantages that extend into the long-term (Weng, Tsai, \& Weng, 2015). The daily tasks of employees working at traditional businesses are generally routine and straightforward, whereas high-tech businesses operate in a dynamic environment characterised by rapid change, uncertainty, and intense competition (Hsia, Chang, \& Tseng, 2014). Employees working in such environments are required to learn efficiently and increase productivity in order to solve the complex problems en-

(CC BY-NC 4.0) This article is licensed to you under a Creative Commons AttributionNonCommercial 4.0 International License. When you copy and redistribute this paper in full or in part, you need to provide proper attribution to it to ensure that others can later locate this work (and to ensure that others do not accuse you of plagiarism). You may (and we encourage you to) adapt, remix, transform, and build upon the material for any non-commercial purposes. This license does not permit you to use this material for commercial purposes. countered by high-tech businesses. Countless businesses have turned to e-learning in order to train employees so that their knowledge, competencies and skills can be efficiently harnessed.

Due to an acceleration in technological progress and the amalgamation of disciplines such as computer science and education, learning has demanded that an accessible environment providing the necessary educational resources be made available (Ryan, 2016; Shafaei, Nejati, Quazi, \& von der Heidt, 
2015; Yanuschik, Pakhomova, \& Batbold, 2015). The integration of information and communication technology (ICT) and educational environments has made valuable contributions to the process of learning and the availability thereof (Drigas, Ioannidou, Kokkalia, \& Lytras, 2014; Özyurt \& Özyurt, 2015; Zhang, Ordóñez de Pablos, \& Zhu, 2012). The inception and development of ICT stresses a focus on a user-oriented system because ICT seeks to solve human-related problems (Jeong \& Park, 2013; Jiang, Klein, Roan, \& Lin, 2001).

e-Learning is the use of ICT to provide information and knowledge resources to learners by relinquishing time and geographic restrictions (Liaw \& Huang, 2013). The use of online resources have been blended together with modern education where information, communication, education and training is delivered online and this forms the foundation of e-learning (Chang, 2016). There are numerous benefits that organisations implementing e-learning can realise, such as cost savings, an improvement in the learning process, an increase in access to instructors for learners, accommodation of various learning styles, dynamic course content, and high-quality training that can be structured or unstructured. Applications of e-learning have been noticed in several areas, including primary and higher education and corporate training as well as training for government employees (Pereira, Ramos, Gouvêa, \& Da Costa, 2015).

The workplace is progressively starting to realise the potential long-term advantages of implementing e-learning. Based on the literature discussed in this section, five categories of advantages to e-learning were identified, namely cost saving, learning improvement, advantages for the learner, advantages for the instructor, and organisational advantages (Figure 1). As indicated in the proposed e-learning success model (Figure 1), these advantages will occur if e-learning is successful. Cost savings are derived since e-learning can provide cost-effective training for employees and customers, resulting in increasing levels of satisfaction and intention to use (Chang, 2016; Chen, 2010). Within the corporate environment, e-learning has been utilised as a popular approach to training and induction due to its attributes of flexibility, ease of access, just-in-time delivery, low costs, consistency, and customer value (Al-Qahtani, Al-Qahtani, \& Al-Miseha, 2013). The advantages of e-learning can be grouped according to cost saving, learning improvement, learner advantages, instructor advantages and organisational advantages (Chang, 2015, 2016; Horton, 2000). Cost savings can be realised with e-learning due to travel, facilities, and supplies becoming superfluous (Figure 1). An improvement in the learning process occurs due to the assistance of e-learning features that can also help to attract learners to be involved in an indepth learning experience. Learners may benefit from being able to access learning resources at any time, from any location and follow a pace suitable to their specific learning style. Two advantages for instructors are, firstly, that they can facilitate learning from any location because traveling is eliminated and, secondly, they can provide dynamic learning content.

One of the main advantages at an organisational level for e-learning is the improved competencies, skills, and knowledge of employees. An organisation's human capital includes knowledge, skills, relationships, competencies, and creativity present in the workforce (Chang, 2016). Setting aside resources in order to invest in human capital is said to put organisations in a better position to be exposed to long-term advantages. By offering and encouraging training for staff in the corporate environment, businesses can realise advantages such as improvements in employee productivity where tasks are completed efficiently and effectively without errors that may have financial and reputational implications. Another benefit of e-learning involves enhancements in the quality of products and services offered due to the increasing competency, skills, and knowledge levels of research and development, sales, marketing, and operations teams and their ability to ensure that outputs are continuously improved. The final benefit of financing employee competency initiatives noted by Chang (2016) is the design and development of competitive strategies, new products, and services resulting from the increased level of competency and collaboration within the organisation. 
Since end-users are considered the key stakeholders in ICT, their attitude towards a system is crucial and should be valued. The focus on end-users is supported by the popularity of the inclusion of user satisfaction as a predictor of information systems' (IS) success (DeLone \& McLean, 2003; Melone, 1990; Raymond, 1987) or to anticipate a user's behaviour of system use or intention to use a system (Gelderman, 1998; C. Lin, Wu, \& Tsai, 2005; H. Lin \& Wang, 2006). The left-hand side of the proposed e-learning success model in Figure 1 is motivated by the arguments from these authors that user satisfaction and intention to use are factors or antecedents of e-learning success.

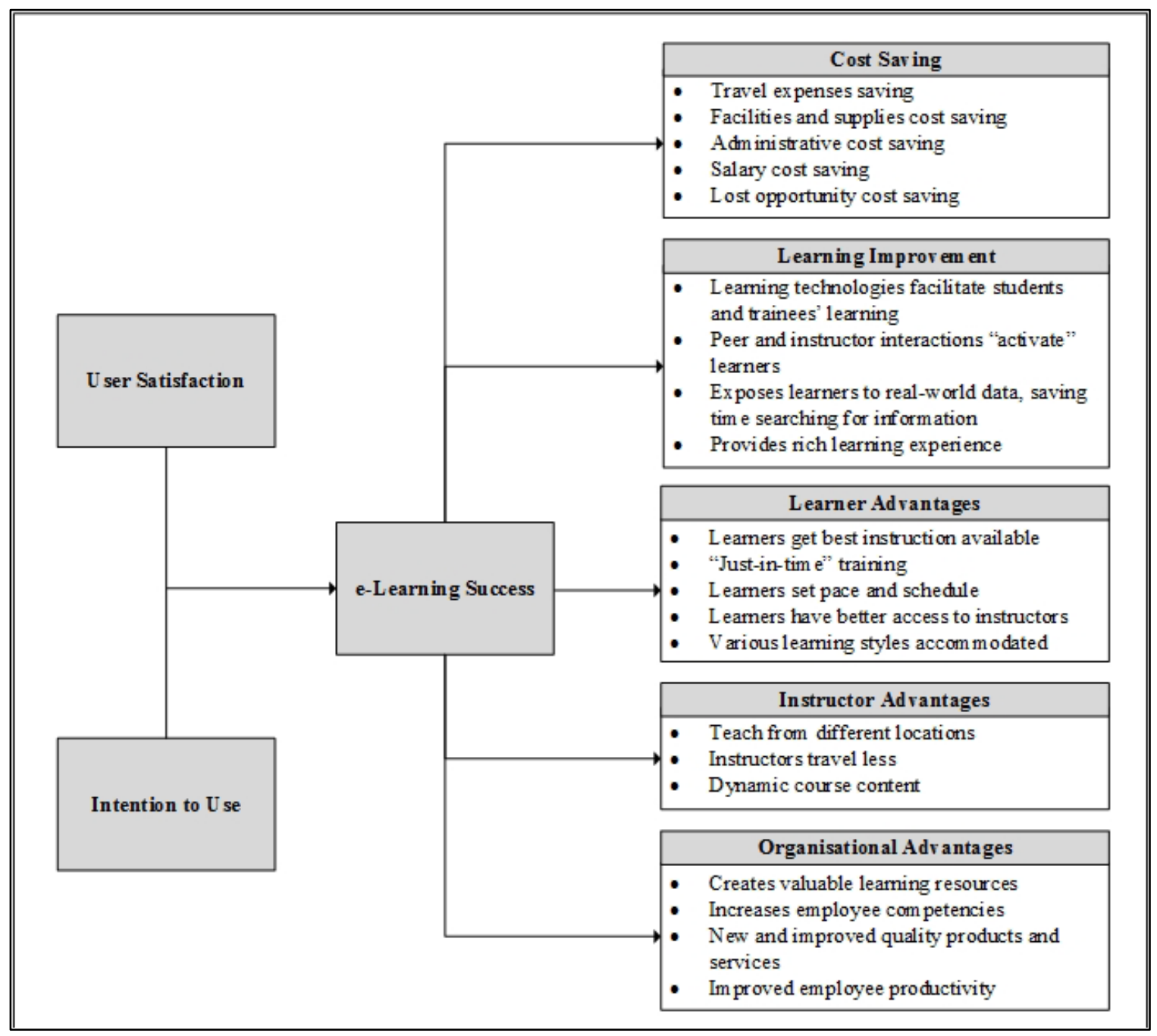

Figure 1. e-Learning Success Model

Because it is complex to prove the return on investment of e-learning, the success of e-learning implementations must be established. e-Learning success can be determined by the behavioural intention to use and user satisfaction thereof (Al-Qahtani et al., 2013; Mohammadi, 2015). Behavioural intention can be defined as an immediate predecessor of usage behaviour and provides an indication of when a user is prepared to execute a particular behaviour (Tarhini, Hone, \& Liu, 2013). The measurement of behavioural intention is suggested as effective for predicting actual usage (Chu \& Chen, 2016; Tarhini et al., 2013). A number of studies have explored the antecedents of technology adoption intention and have highlighted the attitude of users as a central predictor (Hsiao, 2012; Tarhini et al., 2013; Tosuntas, Karadag, \& Orhan, 2015). Chen and Tseng 
Intention and Satisfaction of e-Learning for Corporate Training

(2012) found that motivation and self-efficacy both had significant positive effects while computer anxiety had a significant negative effect on the intention towards the usage of e-learning. Whilst some studies refer to behavioural intention to use or behavioural intention, others refer simply to intention to use and this is the term that will be used henceforth in this paper.

User satisfaction can be conceptualised as the cumulative feeling or attitude toward the many factors that affect a given situation and is envisaged as the manifestation of affections gained from an interaction (Shee \& Wang, 2008). User satisfaction is completely subjective and is influenced by the interaction of the user with the various system components (Lindgaard \& Dudek, 2003). In the IS domain, user satisfaction can be classified as the degree to which users believe that the system in use is conforming to and supporting their requirements (Cyert \& March, 1963).

Whilst the success of e-learning initiatives has become one of the most researched topics in prior literature (Alias, Zakariah, Ismail, \& Aziz, 2012; Klobas, McGill, \& Renzi, 2014; Mohammadi, 2015); most studies that are related to the success of e-learning are conducted in university contexts. There are few articles researching learning satisfaction and learning intention within the corporate space (Wu, Hsieh, \& Lu, 2015). The purpose of this paper is to investigate the intention to use e-learning in corporate organisations as well as the satisfaction thereof. The structure of the paper entails the next section exploring the intention to use e-learning and the satisfaction of using such systems. The subsequent section describes the research methodology and is followed by a discussion of the results of the survey. In the last section, several conclusions and recommendations are made for academia and practitioners alike.

\section{Intention to Use e-Learning}

The success of e-learning initiatives can be determined by the behavioural intention to use elearning, which is also referred to as intention to use (Mohammadi, 2015). Companies that want to avoid the under-utilisation of technological resources must focus on implementing effective strategies to encourage continued usage and participation intentions amongst users (Weng et al., 2015). Research involving intention to use emphasises the investigation of the antecedents that increase intended technology usage in the future (Armenteros, Liaw, Fernández, Díaz, \& Sánchez, 2013; Cheung \& Vogel, 2013; Chu \& Chen, 2016). One of many theoretical models developed to study user behaviour is the theory of reasoned action (TRA), and according to the TRA, the immediate determinant of behaviour is the user's intention to perform or not to perform a given behaviour (Fishbein \& Azjen, 1975). Technology usage intention can be influenced by user attitude and subjective norms. However, when a given behaviour is performed, it can be limited by a shortage of opportunities, skills, and resources (Cheung \& Vogel, 2013). It is for this reason that the TRA was extended using the theory of planned behaviour (TPB) to include an additional variable, namely perceived behavioural control (Azjen, 1991). Perceived behavioural control describes a person's perception of his or her ability to perform a given task and selfefficacy is a component thereof (Cheung \& Vogel, 2013). The components of the TPB model, namely attitudes, subjective norms, and perceived behavioural control, collectively explain behavioural intentions and have been commonly used to investigate user behaviour relating to elearning implementations (Cheung \& Vogel, 2013; Chu \& Chen, 2016; Tarhini et al., 2013).

Smith and Sivo (2012) suggested that by identifying the metrics that could possibly influence the intention to use e-learning, educational managers, designers, and facilitators could align the development and promotion of such systems to ensure that the metrics are accounted for in strategic planning. A study conducted by Chatzoglou, Sarigiannidis, Vraimaki, and Diamantidis (2009) investigated various metrics that, together, can be combined in the form of a model to determine the intention to use e-learning. Perceived usefulness and perceived ease of use are included in the study by Chatzoglou et al. (2009) and originated from the Technology Acceptance Model (TAM). TAM aims to explain the determinants of computer acceptance and consequently the user behav- 
iour across a diverse range of end-user computing technologies and user profiles (Davis, Bagozzi, $\&$ Warshaw, 1989). The remainder of the metrics included in the study are learning goal orientation, management support, self-efficacy, enjoyment, computer anxiety, and intention to use (Chatzoglou et al., 2009).

Management support is the perceived level of general support for web-based training provided by top management which includes encouragement and resource support (Igbaria, Zinatelli, Cragg, \& Cavaye, 1997). The extent to which a person believes that using a computer would enhance job and task-related performance is referred to as perceived usefulness (Arbaugh, 2000; Davis, 1989; Davis et al., 1989; Sun, Ke, \& Cheng, 2007). The degree to which a person believes that using a computer will necessitate minimum or no effort is referred to as perceived ease of use. Learning goal orientation is described as the motivation of individuals to improve their level of competence in order to facilitate task performance improvements by focusing on the learning process (Carson, Mosley, \& Boyar, 2004; Hwang \& Yi, 2002; Printrich, 2000).

Self-efficacy relates to the belief in one's capabilities to initiate one's motivation, cognitive resources, and courses of action required to meet the demands of a given situation (Wood \& Bandura, 1989). According to Bandura (1986), self-efficacy is not associated with the skills one has, but rather with the judgements and belief of what one can do with those skills possessed. Bandura (1986) further explains that self-efficacy will determine what actions to take, how much effort to invest, the length of perseverance, and what methods to use in challenging situations. Self-efficacy has been included in more recent models for systems usage as an antecedent of intention (Henry \& Stone, 1995; Hwang \& Yi, 2003; Venkatesh \& Davis, 2000). Venkatesh (2000) proposed self-efficacy and enjoyment as determinants of ease of use, but did not address their interrelationship. Another study by Hwang and Yi (2003) identified the metric of self-efficacy to have a significant effect on enjoyment.

When referring to enjoyment in the field of IS, it can be defined as the extent to which the task of using the technology or system is perceived as pleasing, regardless of any performance consequences that may be anticipated (Davis, Bagozzi, \& Warshaw, 1992). According to Venkatesh and Speier (2000), enjoyment can be considered a type of intrinsic motivation. Intrinsic motivation is the pursuit of an activity due to a genuine interest or positive feelings associated with the activity (Deci, Koestner, \& Ryan, 1999). Computer anxiety describes the hindrance of the intention of one to use a system due to the anxiety originating from the use of a computer, which in turn hinders one from being able to complete tasks using a computer (Igbaria \& Parasuraman, 1989). Computer anxiety refers to the subjective response and feelings associated with any direct or indirect contact with a computer (Sievert, Albritton, Roper, \& Clayton, 1988). When users have computer anxiety, they may experience feelings of uneasiness, apprehensiveness, or fear when thinking about current or future use of computers. Computer anxiety has been found to impact how people perceive technology (Anderson, 1996; Harrison \& Rainer, 1992). Because the intention to use e-learning measures the future subjective probability of usage behaviour, it is necessary to investigate the user satisfaction of e-learning during the current process of using elearning.

\section{User Satisfaction}

In addition to intention to use, user satisfaction has commonly been used as an antecedent to predict system success (DeLone \& McLean, 2003; Liaw \& Huang, 2013; Melone, 1990; Raymond, 1987). According to Chen (2010), e-learning can be classified as a system. In systems that are highly user-oriented, such as e-learning, users are pivotal to success and therefore their perceptions of the extent to which they are satisfied with using such systems is important (Shee \& Wang, 2008). When used in research, satisfaction can be described as the aggregate of a person's perceptions towards the various factors affecting a given situation (Bailey \& Pearson, 1983). 
When describing user satisfaction relating to human-computer interaction, it is the experience of affections gained from an interaction with a technology, influenced by a variety of components in the interaction (Lindgaard \& Dudek, 2003; Mahmood, Burn, Gemoets, \& Jacquez, 2000). In the field of IS, user satisfaction is the degree to which users perceive that the system they are using addresses and caters for their requirements (Cyert \& March, 1963). Satisfaction can also be explained as the difference between the expected gain or advantage and the actual gain or advantage (Tsai, Yen, Huang, \& Huang, 2007). In the corporate context, user satisfaction refers to the positive emotional state of an employee with reference to working circumstances, supervisors, his or her job duties, and the company as a whole (Yeh, 2014). IS researchers have proven that satisfaction is the most important factor in the success of system implementation and can be influenced by factors related to the student, teacher, course design, technology, system design, and the environment (Teo, 2014). Therefore, a higher level of satisfaction towards a system indicates a higher degree of willingness to use it (Liaw \& Huang, 2013). A study by Kang and Lee (2010) found the metric of enjoyment to be a noticeable antecedent of user satisfaction. Because computer anxiety is a negative reaction towards computer usage, it can affect users' positive responses such as satisfaction (Kang \& Lee, 2010). Companies that thoroughly monitor customer satisfaction can take important precautions to improve their bottom line.

\section{Research Methodology}

The objectives of this paper are to explore and report on the satisfaction of using and the usage intention of e-learning in a corporate context. An in-depth literature review of studies related to the usage intention and satisfaction of using e-learning was undertaken. The theoretical model derived is predominantly based on the model derived by Chatzoglou et al. (2009). The model was updated by the findings of the literature review and according to the context of this study. The model proposes that the success of e-learning usage intention and satisfaction can be determined by measuring three metrics: computer anxiety, self-efficacy, and enjoyment.

\section{Participants}

In order to report on results within a real-world context, an electronic survey was administrated to participants in an established organisation in the South African property industry. The company specialises in the development of technological solutions in the form of software for the industry in which it operates. For purposes of anonymity, the company will be referred to as PropTechSA. The company's vision for e-learning is for it to form an integral part of customers' interaction with their software, especially first time users and when there are new product or feature releases. Prior to the implementation of e-learning, customers were trained to use the software by means of traditional face-to-face courses. PropTechSA would like to transfer these courses to an online environment, in the form of e-learning, in order to reduce costs and to introduce a more effective learning process that is convenient for customers. Some of the courses are partially available online but usage rates of these courses are low. One of PropTechSA's goals is, therefore, to improve the usage of the current e-learning system. In order to do this, the usage intention and satisfaction of using e-learning needs to be investigated so as to devise a strategy to get employees and customers to move from face-to-face training to e-learning resources. As part of establishing the viability of e-learning as a solution for PropTechSA, a preliminary study was undertaken where a focus group and survey were used to identify the needs and profile of PropTech's customer base. The focus group and survey indicated that there are a number of barriers linked to e-learning faced by PropTechSA's customer base, which include a lack of resources such as Internet speed and a lack of social interaction that may be experienced. However, PropTechSA's customers are open to the idea of e-learning and results indicated that it is an option to explore further. 


\section{Research Metrics}

Based on the requirements and scope of this study, it was decided that the metrics to be investigated would be adapted from the metrics used in the study by Chatzoglou et al. (2009) and other relevant literature due to the context of the study. In the respondent pool of this study, there were two groups of respondents: those who have never used an e-learning system before and those who have used or are currently using such a system. This study measured the first group's intention to use an e-learning system and the second group's satisfaction with e-learning, a metric that was not included by Chatzoglou et al. (2009) but has been added for the purpose of this study. It was decided to exclude the metrics of management support and learning goal orientation, since these metrics are outside of the scope of this study. The focus of this study is on the user's behaviour, attitude, and intentions towards e-learning. The metrics of perceived usefulness and perceived ease of use were also omitted due to scope constraints. The metrics chosen from the study by Chatzoglou et al. (2009) were based on their applicability to both groups of respondents, namely self-efficacy, enjoyment, and computer anxiety.

\section{Hypothesis Formulation}

The main objectives of this study are to determine what the intention to use e-learning and the satisfaction of using e-learning is in companies. However, it was decided that it would be interesting to also investigate the relationships between intention, satisfaction, and the three metrics said to influence the aforementioned: self-efficacy, enjoyment, and computer anxiety. In order to meet the objectives, several hypotheses were formulated by following a similar method to Chatzoglou et al. (2009) who undertook a study measuring the intention of employees to accept web-based training.

The hypotheses were identified based on the theory concerning computer anxiety, self-efficacy, enjoyment, intention, and satisfaction of e-learning and were tested at the $95 \%$ significance level $(\alpha=0.05)$. A model of the hypotheses is depicted (Figure 2$)$. The following hypotheses were proposed:
$\mathbf{H}_{1.1}$ : Computer anxiety has a negative effect on intention.
$\mathbf{H}_{1.2}$ : $\quad$ Self-efficacy has a positive effect on intention.
$\mathbf{H}_{1.3}$ : Enjoyment has a positive effect on intention.
$\mathbf{H}_{1.4}$ : Enjoyment and computer anxiety are negatively correlated.
$\mathbf{H}_{1.5}$ : Self-efficacy and computer anxiety are negatively correlated.
$\mathbf{H}_{1.6}$ : Enjoyment and self-efficacy are positively correlated.
$\mathbf{H}_{1.7}$ : Computer anxiety has a negative effect on satisfaction.
$\mathbf{H}_{1.8}$ : Self-efficacy has a positive effect on satisfaction.
$\mathbf{H}_{1.9}$ : Enjoyment has a positive effect on satisfaction. 


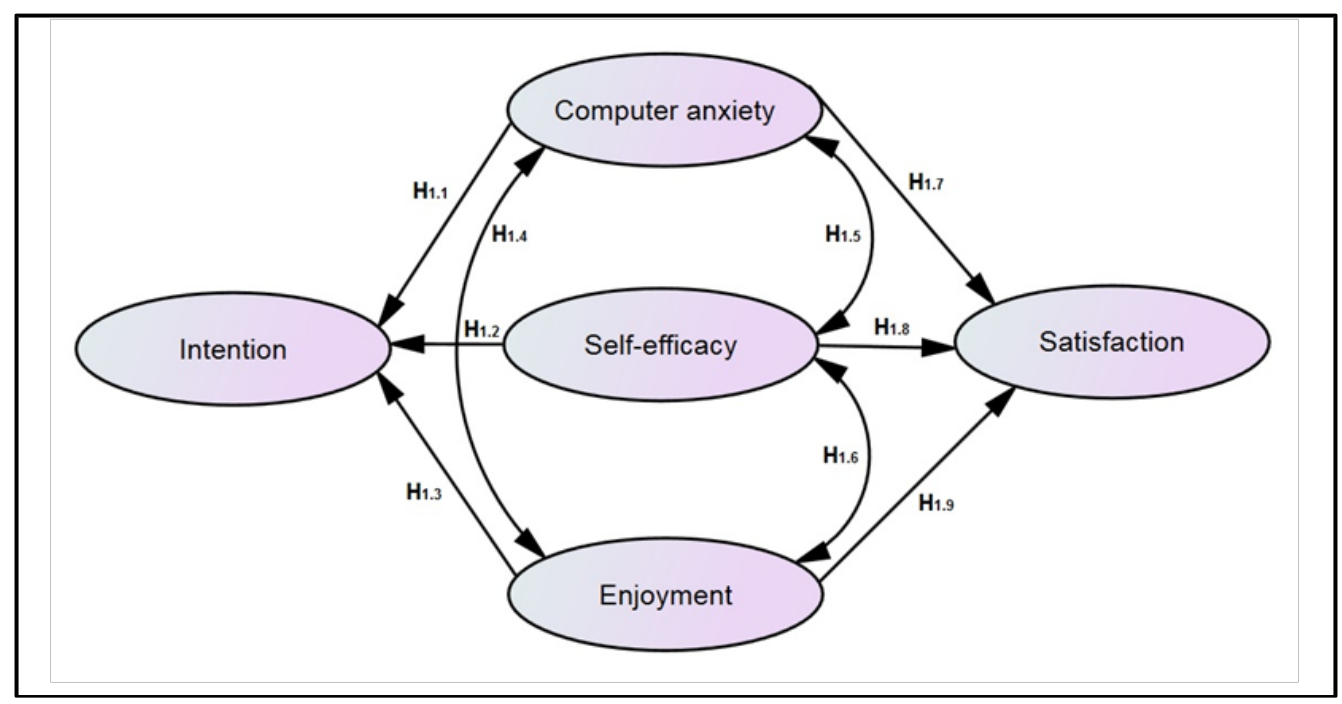

Figure 2. Model for e-Learning Success

\section{Research Materials}

In order to achieve the proposed research objectives, a survey was conducted to measure the usage intention and satisfaction of using e-learning as well as respondents' computer anxiety, selfefficacy, and enjoyment (Appendix). The survey was conducted using an online survey tool, namely Google Forms, where results are captured in a spreadsheet. The survey measured five constructs and the questionnaire is divided into three sections (Figure 3). It was obligatory for all respondents to answer Sections A and B but respondents would only have to answer Section C: Intention or Section D: Satisfaction, depending on whether they have used an e-learning before. The items in the questionnaire used to measure the intended metrics had five-point semantic differential scales where there were opposing levels such as Least preferred and Most preferred.

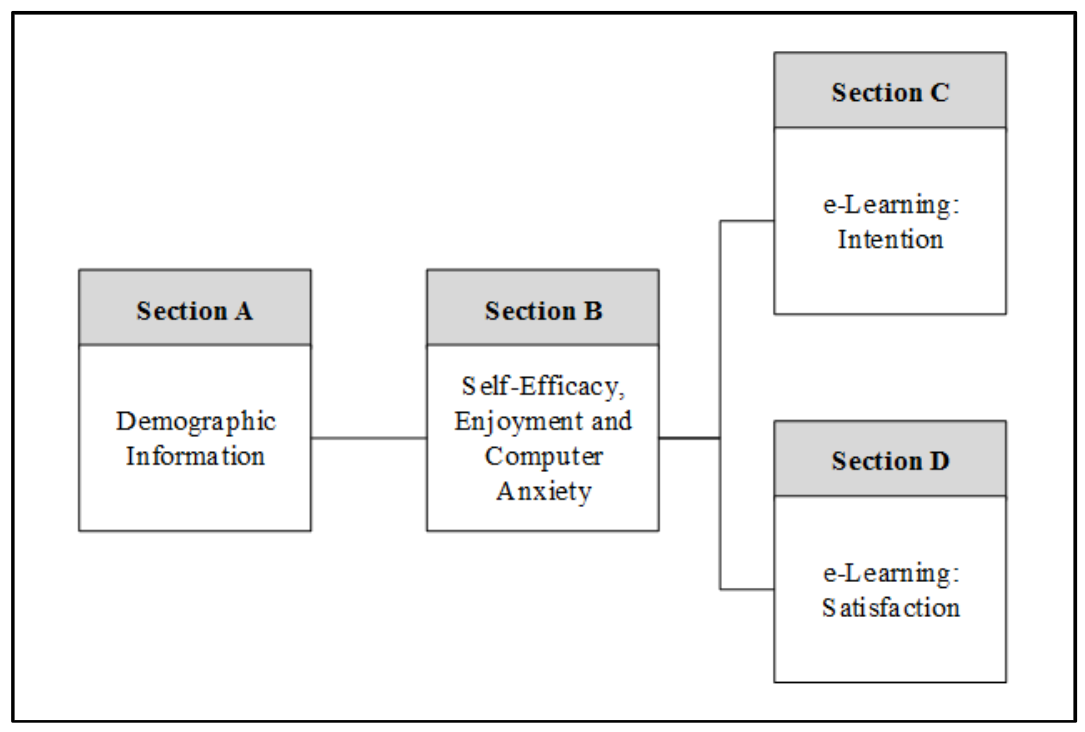

Figure 3. e-Learning Questionnaire Structure

The quality of the survey questions was established by undergoing a pre-testing process (Zikmund, 2003). Two academic expert users and three industry expert users were asked to make 
remarks regarding the research survey instructions and to indicate any issues or lack of clarity of the questionnaire items.

\section{Profile}

Section A of the questionnaire enabled descriptive statistics to be calculated in the form of demographic information (Table 1). Respondents were classified according to their gender, home language, age, highest qualification obtained, and computer experience.

\begin{tabular}{|c|c|c|c|}
\hline \multicolumn{4}{|c|}{ Table 1. Demographic Information $(n=94)$} \\
\hline \multicolumn{2}{|c|}{ Demographic Information } & \multirow{2}{*}{$\begin{array}{c}\text { Frequency (n) } \\
2\end{array}$} & \multirow{2}{*}{$\frac{\text { Percentage }(\%)}{2}$} \\
\hline & Male & & \\
\hline Gender & Female & 92 & 98 \\
\hline \multirow{5}{*}{$\begin{array}{l}\text { Home } \\
\text { Language }\end{array}$} & Afrikaans & 50 & 53 \\
\hline & English & 37 & 39 \\
\hline & Xhosa & 0 & 0 \\
\hline & Other African & 6 & 6 \\
\hline & Other European & 1 & 1 \\
\hline \multirow{4}{*}{ Age } & $18-24$ & 1 & 1 \\
\hline & $25-39$ & 57 & 61 \\
\hline & $40-49$ & 23 & 24 \\
\hline & $50+$ & 13 & 14 \\
\hline \multirow{5}{*}{$\begin{array}{l}\text { Highest } \\
\text { Qualification }\end{array}$} & Some High School & 2 & 2 \\
\hline & High School or equivalent & 64 & 68 \\
\hline & Vocational/Technical School & 12 & 13 \\
\hline & Bachelor's Degree & 8 & 9 \\
\hline & $\begin{array}{l}\text { Honour's Degree or } \\
\text { 4-year equivalent }\end{array}$ & 6 & 6 \\
\hline \multirow{3}{*}{$\begin{array}{l}\text { Computer } \\
\text { Experience }\end{array}$} & Novice user & 2 & 2 \\
\hline & Intermediate user & 41 & 44 \\
\hline & Expert user & 51 & 54 \\
\hline
\end{tabular}

The proportion of female respondents in relation to male respondents is notable. A total of two males $(2 \%)$ and 92 females (98\%) participated in the study, which may appear to be a possible limitation, however, this ratio is representative of the actual customer base of PropTechSA. The majority of the respondents speak Afrikaans (53\%), are between 25 and 39 years of age $(61 \%)$, have a high school or equivalent level of education (68\%), and believe that they are expert computer users $(54 \%)$ who can troubleshoot problems and work without assistance to complete tasks.

\section{Results and Discussion}

Cronbach's alpha statistics were used to establish the reliability, related to internal consistency, of the responses to the questionnaire. The observed quantitative data were analysed to reveal significant relationships between the metrics investigated. When reporting these results, they will be compared with the literature review findings.

\section{Validity and Reliability of Data}

The reliability (internal consistency) of the data obtained from the quantitative feedback was measured using Cronbach's alpha. The Cronbach's alpha coefficients for the five metrics investi- 
gated varied between 0.61 and 0.92 (Table 2). Self-efficacy and enjoyment were the only metrics scoring below the commonly acceptable value of 0.70 , however, some authors argue that a Cronbach's alpha value between 0.60 and 0.70 is acceptable for exploratory research (Gravetter $\&$ Wallnau, 2009). Consequently, the scores derived from the responses to the questionnaire can be considered as fairly reliable.

\begin{tabular}{|l|c|c|}
\hline \multicolumn{3}{|c|}{ Table 2. Cronbach's alpha coefficients - all metrics } \\
\hline Metric & n & Cronbach's $\boldsymbol{\alpha}$ \\
\hline Self-Efficacy & 94 & 0.64 \\
\hline Enjoyment & 94 & 0.61 \\
\hline Computer Anxiety & 94 & 0.76 \\
\hline Intention & 52 & 0.92 \\
\hline Satisfaction & 42 & 0.89 \\
\hline
\end{tabular}

\section{Results}

The structured survey was distributed electronically to the customers who are using PropTechSA's software. Of the 94 respondents, 52 respondents answered a section related to intention to use and 42 respondents answered a section related to the satisfaction of using e-learning, based on whether or not an e-learning system had been used previously. The respondents had varying levels of expertise and familiarity in the field of e-learning in the corporate context. Each metric measured by the survey was calculated as the average of the responses to the relevant set of items in the questionnaire using a semantic differential response scale of 1 to 5. The results for each scale item revealed the respondents' perception of the five metrics measured (Table 3). Metric scores were classified according to the ranges depicted in the column headings of the frequency distributions for the metrics where square brackets indicate inclusion in the relevant interval and parentheses depict exclusion.

\begin{tabular}{|c|c|c|c|c|c|c|c|c|c|c|}
\hline \multicolumn{11}{|c|}{ Table 3. Frequency distributions - all metrics } \\
\hline \multirow[b]{2}{*}{ Self-Efficacy } & \multicolumn{2}{|c|}{$\begin{array}{l}\text { Very Negative } \\
\text { [1.00 to } 1.80 \text { ) }\end{array}$} & \multicolumn{2}{|c|}{$\begin{array}{c}\text { Negative } \\
{[1.80 \text { to } 2.60)}\end{array}$} & \multicolumn{2}{|c|}{$\begin{array}{c}\text { Neutral } \\
{[2.60 \text { to } 3.40]}\end{array}$} & \multicolumn{2}{|c|}{$\begin{array}{c}\text { Positive } \\
\text { (3.40 to 4.20] }\end{array}$} & \multicolumn{2}{|c|}{$\begin{array}{l}\text { Very Positive } \\
\text { (4.20 to 5.00] }\end{array}$} \\
\hline & 0 & $0 \%$ & 0 & $0 \%$ & 8 & $9 \%$ & 9 & $10 \%$ & 77 & $82 \%$ \\
\hline Enjoyment & 0 & $0 \%$ & 2 & $2 \%$ & 4 & $4 \%$ & 21 & $22 \%$ & 67 & $71 \%$ \\
\hline $\begin{array}{l}\text { Computer } \\
\text { Anxiety }\end{array}$ & 87 & $93 \%$ & 6 & $6 \%$ & 0 & $0 \%$ & 1 & $1 \%$ & 0 & $0 \%$ \\
\hline Intention & 2 & $4 \%$ & 2 & $4 \%$ & 5 & $10 \%$ & 11 & $21 \%$ & 32 & $62 \%$ \\
\hline Satisfaction & 0 & $0 \%$ & 0 & $0 \%$ & 8 & $19 \%$ & 2 & $5 \%$ & 32 & $76 \%$ \\
\hline
\end{tabular}

More than $60 \%$ of the respondents rated four of the five metrics (self-efficacy, enjoyment, intention, and satisfaction) as Very Positive. Self-efficacy had the highest incidence of very positive ratings $(82 \%)$. Computer anxiety was rated very negatively by the largest portion of respondents (93\%) which is a positive result because a negative computer anxiety result implies that the respondents have a constructive perception regarding their capabilities concerning the tasks that they carry out using a computer. From this it can be deduced that respondents are confident in their ability to use a computer to meet everyday demands and do not fear the use of computers.

Measures of central tendency, namely mean, and dispersion, namely standard deviation, were calculated for the five metrics measured in this study (Table 4). The overall mean ratings show that respondents rated their self-efficacy the highest $(\mathrm{M}=4.58)$, a very positive score, and com- 
puter anxiety the lowest $(\mathrm{M}=1.19)$ a very negative score. Since computer anxiety may negatively affect the intention to use a system, a negative rating for computer anxiety is a positive result which is a similar result to that obtained by Chatzoglou et al. (2009) where computer anxiety also obtained a negative rating. Satisfaction $(M=4.52)$ and Enjoyment $(M=4.50)$ obtained very positive mean scores and Intention $(\mathrm{M}=4.18)$ a positive mean score.

\begin{tabular}{|l|c|c|c|}
\hline \multicolumn{4}{|c|}{ Table 4. Overall Mean and Standard Deviation } \\
\hline \multirow{2}{*}{ Metric } & & $\begin{array}{c}\text { Overall Mean } \\
\text { Rating }\end{array}$ & $\begin{array}{c}\text { Overall Standard } \\
\text { Deviation }\end{array}$ \\
\cline { 2 - 4 } & $\mathbf{n}$ & $\mathbf{M}$ & $\mathbf{S}$ \\
\hline Self-Efficacy & 94 & 4.58 & 0.82 \\
\hline Enjoyment & 94 & 4.50 & 0.88 \\
\hline Computer Anxiety & 94 & 1.19 & 0.58 \\
\hline Intention & 52 & 4.18 & 1.08 \\
\hline Satisfaction & 42 & 4.52 & 0.87 \\
\hline
\end{tabular}

Correlations between the metrics are reflected in Table 5. Correlations are deemed significant if they are both statistically and practically significant. Statistical significance depends on the significance level and sample size, for example, for a 0.05 significance level and sample size $n=94$ (number of respondents for this study), the absolute value of a correlation's coefficient must be greater than 0.203 to be statistically significant, whilst correlations greater than 0.300 are deemed practically significant (Gravetter \& Wallnau, 2009). In Table 5, significant correlations between the metrics are indicated as bold red and italics while correlations that are statistically but not practically significant are depicted as plain red.

\begin{tabular}{|l|c|c|c|c|c|}
\hline \multicolumn{7}{|c|}{ Table 5. Pearson Product Moment Correlations - all metrics } \\
\hline & Self-Efficacy & Enjoyment & $\begin{array}{c}\text { Computer } \\
\text { Anxiety }\end{array}$ & Intention & Satisfaction \\
\hline Self-Efficacy & - & $\mathbf{0 . 5 0 5}$ & -0.267 & 0.178 & 0.284 \\
\hline Enjoyment & $\mathbf{0 . 5 0 5}$ & - & -0.240 & 0.209 & $\mathbf{0 . 3 3 8}$ \\
\hline Computer Anxiety & -0.267 & -0.240 & - & -0.164 & -0.005 \\
\hline Intention & 0.178 & 0.209 & -0.164 & - & - \\
\hline Satisfaction & 0.284 & $\mathbf{0 . 3 3 8}$ & -0.005 & - & - \\
\hline
\end{tabular}

Two significant relationships were identified: between enjoyment and self-efficacy $(r=0.505)$ and between enjoyment and satisfaction $(r=0.338)$. A number of relationships were identified as statistically significant but not practically significant and these were:

- Self-efficacy and computer anxiety $(r=-0.267)$;

- Self-efficacy and satisfaction ( $\mathrm{r}=0.284)$;

- Enjoyment and computer anxiety $(\mathrm{r}=-0.240)$; and

- Enjoyment and intention $(r=0.209)$.

Hypotheses regarding the relationships between enjoyment and self-efficacy $\left(\mathrm{H}_{1.6}\right)$ and between enjoyment and satisfaction $\left(\mathrm{H}_{1.9}\right)$ are supported by the results of the statistical analysis and thus are accepted (Table 6). The strongest direct relationship was between enjoyment and self-efficacy $(\mathrm{r}=0.505)$ and this confirms that an interesting and fulfilling training program may lead trainees 
to establish new initiatives, to overcome complex job-related problems, and to improve their selfesteem related to their jobs, which has been confirmed in earlier studies (Chatzoglou et al., 2009; Hwang \& Yi, 2003). The second strongest direct relationship was between enjoyment and satisfaction $(\mathrm{r}=0.338)$. From this it can be deduced that trainees use e-learning because they believe that the training process is interesting, helpful, and enjoyable, and because of this trainees are pleased to use it. Alternatively, if trainees think that e-learning will be boring and of no real value for the trainee, they will not be enthusiastic and motivated enough to participate in the training process. This result is consistent with the relationship established by Kang and Lee (2010) between enjoyment and satisfaction. The remaining seven hypotheses originally proposed are not accepted since the relevant correlations are not significant. In summary, by considering the results of the Pearson Product Moment correlations, the following statement can be made:

\section{" $H_{1.6}$ and $H_{1.9}$ are accepted as there is a significant relationship between enjoyment and self- efficacy and between enjoyment and satisfaction."}

\begin{tabular}{|l|l|l|}
\hline \multicolumn{3}{|c|}{ Table 6. Hypothesis testing results } \\
\hline Hypothesis & Relationship & Remarks \\
\hline $\mathbf{H}_{\mathbf{1 . 1}}$ & Computer anxiety $\rightarrow$ intention $(-)$ & Not accepted \\
\hline $\mathbf{H}_{1.2}$ & Self-efficacy $\rightarrow$ intention $(+)$ & Not accepted \\
\hline $\mathbf{H}_{1.3}$ & Enjoyment $\rightarrow$ intention $(+)$ & Not accepted \\
\hline $\mathbf{H}_{1.4}$ & Enjoyment $\leftrightarrow$ computer anxiety $(-)$ & Not accepted \\
\hline $\mathbf{H}_{1.5}$ & Self-efficacy $\leftrightarrow$ computer anxiety $(-)$ & Not accepted \\
\hline $\mathbf{H}_{1.6}$ & Enjoyment $\leftrightarrow$ self-efficacy $(+)$ & Accepted \\
\hline $\mathbf{H}_{1.7}$ & Computer anxiety $\rightarrow$ satisfaction $(-)$ & Not accepted \\
\hline $\mathbf{H}_{1.8}$ & Self-efficacy $\rightarrow$ satisfaction $(+)$ & Not accepted \\
\hline $\mathbf{H}_{1.9}$ & Enjoyment $\rightarrow$ satisfaction $(+)$ & Accepted \\
\hline
\end{tabular}

\section{Conclusions and Recommendations}

This study aimed to investigate and report on the intention and satisfaction of using e-learning from a corporate perspective. An in-depth literature review was conducted to develop an understanding of intention and satisfaction in the field of e-learning and a theoretical model was proposed, based on an adaptation of the model by Chatzoglou et al. (2009) and other literature. The model proposed three prominent antecedents that can influence the intention and satisfaction of elearning, namely enjoyment, self-efficacy, and computer anxiety. The results of a survey of PropTechSA's customer base identified positive levels of self-efficacy, enjoyment, satisfaction, and intention to use amongst the respondents. The positive results for enjoyment and self-efficacy as well as the negative result for computer anxiety correlate with literature (Chatzoglou et al., 2009; Davis et al., 1992). Computer anxiety was rated negatively, which is a positive result since high anxiety can negatively affect intention to use e-learning. Therefore, if trainees have high computer anxiety levels, they are not confident to use computers for the training program and could exert little effort into the training process. Based on the positive mean score for intention to use e-learning observed in this study it can be deduced that the customers of PropTechSA do intend to use e-learning in order to learn to use the software provided by the company. It is also evident from the observed positive mean satisfaction score that the respondents currently using elearning for training are satisfied with their experience thus far because of their positive emotional state due to the ability of e-learning to meet their learning requirements (Cheok \& Wong, 2015; Yeh, 2014).

This study has identified important metrics that can be used by companies to determine the potential success of e-learning initiatives and prioritised in online training strategies in order to ensure 
trainee satisfaction and intended future usage. Positive intention to use and satisfaction levels can provide PropTechSA the evidence that e-learning is worth investing resources in so that the chance of benefiting from the many advantages e-learning offers (Figure 1) is higher. Enjoyment was found to play an important role in the establishment of user satisfaction and self-efficacy. This finding is perhaps the most important managerial lesson to be learned from this study for practitioners because, nowadays, managers tend to believe that the importance of pleasure derived from system usage diminishes as the system matures and user tasks become mundane. It is important therefore that the metrics of enjoyment, self-efficacy, and satisfaction are considered in the strategic plans for e-learning in organisations.

Whilst the literature motivated the nine hypotheses, only two of these (enjoyment $\rightarrow$ self-efficacy and enjoyment $\rightarrow$ satisfaction) were supported and not the others. The analysis of the results revealed that there were no significant relationships between the three antecedents (computer anxiety, self-efficacy, and enjoyment) and intention. These results contradict the studies of Chen and Tseng (2012) and Kang and Lee (2010) who found that anxiety had a negative effect on intention. It also contradicts the study of Hwang and Yin (2003) who found that a user's self-efficacy had an impact on intention to use a web-based system. Lastly, the results are contrary to the findings of Kang and Lee (2010), who found that computer anxiety can negative impact users' positive responses such as satisfaction.

It is not clearly evident at first why the findings contradicted the literature, thereby resulting in seven of the nine hypotheses not being accepted. However, the contradiction could be due to the particular context in which the respondent customers work. As identified by Yeh (2014), the working circumstances, supervisors, and tasks of the users could play a role in e-learning satisfaction. Factors related to working conditions were not considered in this study and is possibly a limitation. Another reason could be because of the type of software investigated, or due to the fact that the respondents were a mixed sample of users which included some that had used e-learning before and others who hadn't. The experience of the user with e-learning systems and other related systems could also influence the results. Future research could conduct a longitudinal study with a broader profile of users and possibly consider more factors. The investigation of a larger sample of metrics could improve the hypothesis testing results. A larger sample will allow more sophisticated statistical analysis to be conducted. This research could be extended to other contexts such as companies operating in construction, manufacturing, banks, or companies in different countries in order to broaden the research of e-learning in the corporate context, which is currently lacking.

\section{Acknowledgements}

This work is based on the research supported in part by the National Research Foundation of South Africa (Grant Number 94506).

\section{References}

Alias, N., Zakariah, Z., Ismail, N., \& Aziz, M. N. (2012). E-Learning successful elements for higher learning institution in Malaysia. Procedia - Social and Behavioral Sciences, 67, 484-489.

Al-Qahtani, M., Al-Qahtani, M., \& Al-Misehal, H. (2013). Learner satisfaction of e-learning in workplace: Case of oil company in Middle East. 2013 Tenth International Conference on Information Technology: New Generations (ITNG), 294-298.

Anderson, A. A. (1996). Predictors of computer anxiety and performance in information systems. Computers in Human Behavior, 12(1), 61-77.

Arbaugh, J. B. (2000). Virtual classroom characteristics and student satisfaction with internet-based MBA courses. Journal of Management Education, 24(1), 32-54. 
Armenteros, M., Liaw, S. S., Fernández, M., Díaz, R. F., \& Sánchez, R. A. (2013). Surveying FIFA instructors' behavioral intention toward the multimedia teaching materials. Computers and Education, 61(1), 91-104.

Azjen, I. (1991). The theory of planned behavior. Organizational Behavior and Human Decision Processes, 50(2), 179-211.

Bailey, J. E., \& Pearson, S. W. (1983). Development of a tool for measuring and analyzing computer user satisfaction. Management Science, 29(5), 530-545.

Bandura, A. (1986). Social foundations of thought and action: A social cognitive theory. Englewood Cliffs, NJ: Prentice-Hall.

Carson, C. M., Mosley, D. C., \& Boyar, S. L. (2004). Goal orientation and supervisory behaviors: Impacting SMWT effectiveness. Team Performance Management, 10(7), 152-162.

Chang, V. (2015). The role and effectiveness of e-learning for the industry. Lambert.

Chang, V. (2016). Review and discussion: e-Learning for academia and industry. International Journal of Information Management.

Chatzoglou, P., Sarigiannidis, L., Vraimaki, E., \& Diamantidis, A. (2009). Investigating Greek employees' intention to use web-based training. Computers and Education, 53(3), 877-889.

Chen, H. (2010). Linking employees' e-learning system use to their overall job outcomes: An empirical study based on the is success model. Computers and Education, 55(4), 1628-1639.

Chen, H. R., \& Tseng, H. F. (2012). Factors that influence acceptance of web-based e-learning system for the in-service education of junior high schooll teachers in Taiwan. Evaluation and Program Planning, 35(3), 398-406.

Cheok, M., \& Wong, S. (2015). Predictors of e-learning satisfaction in teaching and learning for school teachers: A literature review. International Journal of Instruction, 8(1).

Cheung, R., \& Vogel, D. (2013). Predicting user acceptance of collaborative technologies: An extension of the technology acceptance model for e-learning. Computers and Education, 63, 160-175.

Chu, T. H., \& Chen, Y. Y. (2016). With good we become good: Understanding e-learning adoption by theory of planned behavior and group influences. Computers and Education, 92(C), 37-52.

Cyert, R. M., \& March, J. G. (1963). A behavior theory of the firm. Englewood Cliffs, NJ: Prentice-Hall.

Davis, F. D. (1989). Perceived usefulness, perceived ease of use, and user acceptance of information technologies. MIS Quarterly, 13(3), 319-340.

Davis, F. D., Bagozzi, R., \& Warshaw, P. R. (1989). User acceptance of computer technology: A comparison of two theoretical models. Management Science, 35(8), 982-1003.

Davis, F. D., Bagozzi, R., \& Warshaw, P. R. (1992). Extrinsic and intrinsic motivation to use computers in the workplace. Journal of Applied Social Psychology, 22(14), 1111-1132.

Deci, E., Koestner, R., \& Ryan, R. (1999). A meta-analytic review of experiments examining the effects of extrinsic rewards on intrinsic motivation. Psychological Bulletin, 627-668.

DeLone, W. H., \& McLean, E. R. (2003). The DeLone and McLean model of information systems success: A ten-year update. Journal of Management Information Systems, 19(4), 9-30.

Drigas, A. S., Ioannidou, R. E., Kokkalia, G., \& Lytras, M. D. (2014). ICTs, mobile learning and social media to enhance learning for attention difficulties. Journal of Universal Computer Science, 20(10), 1499-1510.

Fishbein, M., \& Azjen, I. (1975). Belief, attitude, intention and behavior: An introduction to theory and research. Reading, MA: Addison-Wesley.

Gelderman, M. (1998). The relation between user satisfaction, usage of information systems and performance. Information and Management, 34(1), 11-18. 
Gravetter, F., \& Wallnau, L. (2009). Statistics for the behavioral sciences. (8th ed.). Belmont, CA: Cengage Learning.

Harrison, A. W., \& Rainer, R. K. J. (1992). The influence of individual differences on skill in end-user computing. Journal of Management Information Systems, 9(1), 93-111.

Henry, J. W., \& Stone, R. W. (1995). A structural equation model of job performance using a computerbased order entry system. Behavior and Information Technology, 14(3), 163-173.

Horton, W. (2000). Designing web-based training (1st ed.). Wiley \& Sons.

Hsia, J.W., Chang, C.C., \& Tseng, A.H. (2014). Effects of individuals' locus of control and computer selfefficacy on their e-learning acceptance in high-tech companies. Behaviour \& Information Technology, $33(1), 51-64$.

Hsiao, K. (2012). Exploring the factors that influence continuance intention to attend on-to-some online course via videoconferencing software. The Turkish Online Journal of Educational Technology, 11(4), $155-163$.

Hwang, Y., \& Yi, M. Y. (2002). Predicting the use of web-based information systems: Intrinsic motivation and self-efficacy. In Proceedings of the Eighth Americas Conference on Information Systems (pp. 1076-1081).

Hwang, Y., \& Yi, M. Y. (2003). Predicting the use of web-based information systems: self-efficacy, enjoyment, learning goal orientation, and the technology acceptance model. International Journal of Human-Computer Studies, 59(4), 431-449.

Igbaria, M., \& Parasuraman, S. (1989). A path analytic study of individual characteristics, computer anxiety and attitudes toward microcomputers. Journal of Management, 15(3), 373-388.

Igbaria, M., Zinatelli, N., Cragg, P., \& Cavaye, A. L. M. (1997). Personal computing factors in small firms: A structural equation model. MIS Quarterly, 21(3), 279-305.

Jeong, H. Y., \& Park, J. H. (2013). Service based user oriented adaptive learning system. 16th International Conference on Network-Based Information Systems, 292-295.

Jiang, J. J., Klein, G., Roan, J., \& Lin, J. T. M. (2001). IS service performance: Self-perceptions and user perceptions. Information \& Management, 38(8), 499-506.

Kang, Y. S., \& Lee, H. (2010). Understanding the role of an IT artifact in online service continuance: An extended perspective of user satisfaction. Computers in Human Behavior, 26(3), 353-364.

Klobas, J. E., McGill, T. J., \& Renzi, S. (2014). Critical success factors for the continuation of e-learning initiatives. The Internet and Higher Education, 22, 24-36.

Liaw, S. S., \& Huang, H. M. (2013). Perceived satisfaction, perceived usefulness and interactive learning environments as predictors to self-regulation in e-learning environments. Computers and Education, $60(1), 14-24$.

Lin, C., Wu, S., \& Tsai, R. (2005). Integrating perceived playfulness into expectation-confirmation model for web portal context. Information \& Management, 42(5), 683-693.

Lin, H., \& Wang, Y. (2006). An examination of the determinants of customer loyalty in mobile commerce contexts. Information \& Management, 43(3), 271-282.

Lindgaard, G., \& Dudek, C. (2003). What is this evasive beast we call user satisfaction? Interacting with Computers, 15(3), 429-452.

Mahmood, M. A., Burn, J. M., Gemoets, L. A., \& Jacquez, C. (2000). Variables affecting information technology end-user satisfaction: A meta-analysis of the empirical literature. International Journal of Human-Computer Studies, 52(4), 751-771.

Melone, N. P. (1990). A theoretical assessment of the user-satisfaction construct in information systems research. Management Science, 36(1), 76-91. 
Mohammadi, H. (2015). Investigating users' perspectives on e-learning: An integration of tam and is success model. Computers in Human Behavior, 45(April), 359-374.

Özyurt, Ö., \& Özyurt, H. (2015). Learning style based individualized adaptive e-learning environments: Content analysis of the articles published from 2005 to 2014. Computers in Human Behavior, 52, 349358.

Pereira, F. A., Ramos, A. S., Gouvêa, M., \& Da Costa, M. (2015). Satisfaction and continuous use intention of e-learning service in Brazilian public organizations. Computers in Human Behavior, 46, 139-148.

Printrich, P. (2000). Multiple goals, multiple pathways: The role of goal orientation in learning and achievement. Journal of Educational Psychology, 92, 545-555.

Raymond, L. (1987). Validating and applying user satisfaction as a measure of mis success in small organization. Information and Management, 12(4), 173-179.

Ryan, J. (2016). "Asian" learners or "internationalised" learners? Taking advantage of international cultural academic flows. East Asia, 33(1), 9-24.

Shafaei, A., Nejati, M., Quazi, A., \& von der Heidt, T. (2015). "When in Rome, do as the Romans do" Do international students' acculturation attitudes impact their ethical academic conduct? Higher Education, 1-16.

Shee, D., \& Wang, Y. (2008). Multi-criteria evaluation of the web-based e-learning system: A methodology based on learner satisfaction and its applications. Computers and Education, 50(3), 894 905.

Sievert, M. E., Albritton, R. L., Roper, P., \& Clayton. N. (1988). Investigating computer anxiety in an academic library. Information Technology and Libraries, 7(3), 243-252.

Smith, J., \& Sivo, S. (2012). Predicting continued use of online teacher professional development and the influence of social presence and sociability. British Journal of Educational Technology, 43(6), 871882.

Sun, J., Ke, Q., \& Cheng, Y. (2007). Study of consumer acceptance in e-commerce by integrating technology acceptance model with task-technology fit model. In International Conference on Wireless Communications, Networking and Mobile Computing (WiCom) (pp. 3621-3624).

Tarhini, A., Hone, K., \& Liu, X. (2013). Extending the TAM model to empirically investigate the students' behavioural intention to use e-learning in developing countries. Science and Information Conference (SAI), 732-737.

Teo, T. (2014). Preservice teachers' satisfaction with e-learning. Social Behavior and Personality: An International Journal, 42(1), 3-6.

Tosuntas, S. B., Karadag, B. E., \& Orhan, S. (2015). The factors affecting acceptance and use of interactive whiteboard within the scope of FATIH project: A structural equation model based on the unified theory of acceptance and use of technology. Computers \& Education, 81, 169-178.

Tsai, P. C., Yen, Y., Huang, L., \& Huang, I. (2007). A study on motivating employees' learning commitment in the post-downsizing era: Job satisfaction perspective. Journal of World Business, $42(2), 157-169$.

Venkatesh, V. (2000). Determinants of perceived ease of use: Integrating control, intrinsic motivation, and emotion into the technology acceptance model. Information Systems Research, 11, 342-365.

Venkatesh, V., \& Davis, F. D. (2000). A theoretical extension of the technology acceptance model: Four longitudinal field studies. Management Science, 46(2), 186-204.

Venkatesh, V., \& Speier, C. (2000). Creating an effective training environment for enhancing telework. International Journal of Human-Computer Studies, 52, 991-1005. 
Weng, C., Tsai, C., \& Weng, A. (2015). Social support as a neglected e-learning motivator affecting trainee's decisions of continuous intentions of usage. Australasian Journal of Educational Technology, 31(2), 177-192.

Wood, R., \& Bandura, A. (1989). Impact of conceptions of ability on self-regulatory mechanisms and complex decision making. Journal of Personality and Social Psychology, 56(3), 407-415.

Wu, Y.C., Hsieh, L.F., \& Lu, J.J. (2015). What's the relationship between learning satisfaction and continuing learning intention? Procedia - Social and Behavioral Sciences, 191, 2849-2854.

Yanuschik, O. V, Pakhomova, E. G., \& Batbold, K. (2015). e-Learning as a way to improve the quality of education for international students. Procedia - Social and Behavioral Sciences, 215, 147-155.

Yeh, Y. (2014). Exploring the impacts of employee advocacy on job satisfaction and organizational commitment: Case of Taiwanese airlines. Journal of Air Transport Management, 36, 94-100.

Zhang, X., Ordóñez de Pablos, P., \& Zhu, H. (2012). The impact of second life on team learning outcomes from the perspective of IT capabilities. International Journal of Engineering Education, 28(6), 13881392.

Zikmund, W. (2003). Business research methods (7th ed.). Mason: Thomson/South-Western. 


\section{Appendix}

\section{Survey Items}

\section{Self-Efficacy}

$1=$ Extremely Disagree to 5 = Extremely Agree (for all 4 items)

SE1 I feel confident using a computer without any assistance.

SE2 I find it easy to adapt to new software versions.

SE3 When faced with a problem whilst using a computer, I try solving it myself before calling for assistance.

SE4 If I cannot solve a problem on my first attempt whilst using a computer, I try again.

\section{Enjoyment}

$1=$ Extremely Disagree to $5=$ Extremely Agree (for all 3 items)

ENJ1 Using computers to complete daily tasks is pleasant.

ENJ2 I have fun solving problems using a computer.

ENJ3 Because using a computer allows me to accomplish tasks, I feel innovative.

\section{Computer Anxiety}

$1=$ Extremely Disagree to $5=$ Extremely Agree (for all 4 items)

CA1 I hesitate to use a computer for fear of losing work that cannot be recovered.

CA2 Computers are intimidating to me.

CA3 I fear that I won't be able to progress with my work as a result of errors made whilst using a computer.

CA4 I have a fear of unfamiliar technology.

\section{Intention}

$1=$ Extremely Unlikely to $5=$ Extremely Likely (for all 4 items)

INT1 I intend to use e-learning for training when it will be implemented.

INT2 I intend to use e-learning for training in order to improve my performance.

INT3 I intend to use e-learning for training on a regular basis.

INT4 My intention is to use e-learning instead of requesting assistance (using call centre, live chat, face-to-face training).

\section{Satisfaction}

$1=$ Extremely Disagree to $5=$ Extremely Agree (for all 5 items)

SA1 I achieved my learning goals using e-learning.

SA2 Using e-learning helped me to improve my performance.

SA3 I was satisfied with using e-learning for training.

SA4 I would use e-learning for training on a regular basis.

SA5 I would recommend using e-learning for training to my colleagues. 


\section{Biographies}

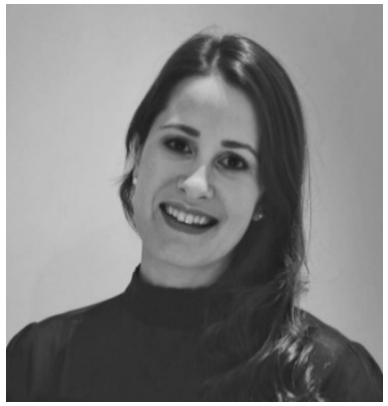

Maxine Esterhuyse is currently pursuing her Masters degree in Information Systems and Computer Science at the Nelson Mandela Metropolitan University (NMMU) in Port Elizabeth, South Africa. Maxine works as a junior lecturer for business information systems at the university. She manages an e-learning project for the university and is currently involved in end-user software training that takes place in a face-to-face setting. Her research interests are e-learning, enterprise systems, human-computer interaction and business intelligence.

Maxine has a number of research papers published on the subject of elearning. Several of her conference papers were presented at conferences affiliated with the Association for Information Systems (AIS).

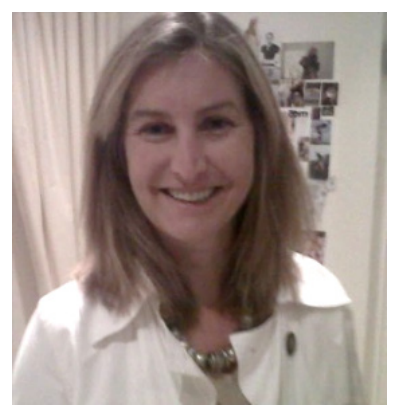

Brenda Scholtz (Ph.D.) is Head of Department for Computing Sciences at the Nelson Mandela Metropolitan University (NMMU) in Port Elizabeth. Brenda has worked in the IT industry for over 15 years as programmer, systems analyst, consultant and IT manager. She was awarded her PhD in ERP skills and education in 2012. Her research interests are in the broad field of Information Systems, more specifically related to business process management, enterprise systems, business intelligence, enterprise architectures and environmental information systems. Brenda is currently serving as project manager for several industry research collaboration programmes between South Africa and Germany. Brenda is also a member of the Institute of Information Technology Professionals South Africa (IITPSA), the Association for Information Systems (AIS) as well as the Business Architecture Guild. Brenda has published over 48 papers in international journals and conferences.

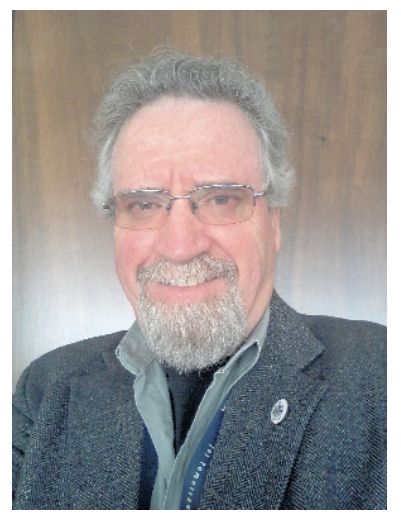

Danie Venter obtained his BSc from UNISA and his BSc Hons, MSc and $\mathrm{PhD}$ (2014) degrees from the Nelson Mandela Metropolitan University (NMMU), the first two degrees in Computer Science and the last two in Statistics. He has been a quantitative research consultant in the NMMU Unit for Statistical Consultation and a similar entity in its predecessor the University of Port Elizabeth (UPE) since 1990. He was the director of these entities until the end of 2015 when he reached retirement age. Since then he has been reappointed on a contract basis.

He has collaborated with colleagues in various NMMU/UPE faculties and researchers at other universities in numerous quantitative research projects, with more than 100 articles in accredited journals and many presentations at local and international conferences. He has assisted a

large number of Master's and Doctoral students (more than a 1000) during all stages of their quantitative research projects, in more than 60 instances formally in a supervisory capacity. He has also been involved as the main statistical consultant in numerous research projects in the private sector. His main research areas are industrial psychology, business management, computer science, human movement and other health sciences. His fields of expertise include: the measurement of latent variables (e.g. job satisfaction, health risks); questionnaire development; forecasting; effect size; the development of data processing and analysis applications in VBA on an Excel platform. 